\title{
Perancangan Online Market Place Makanan Tradisional Untuk Usaha Kecil dan Menengah di Surabaya
}

\author{
Didit Prasetyo $^{1^{*}}$, Putri Dwitasari ${ }^{2}$, Nurina Orta Darmawati ${ }^{3}$ \\ 1,2,3 Desain Komunikasi Visual, Fakultas Arsitektur Desain dan Perencanaan, \\ Institut Teknologi Sepuluh Nopember, Jl. Despro, ITS, Sukolilo, Surabaya \\ *Penulis korespondensi; Email: diditdkv@gmail.com
}

\begin{abstract}
Abstrak
Perkembangan teknologi yang pesat di saat sekarang ini membawa konsekuensi terjadinya disrupsi, perubahan pola hidup dan perubahan gaya hidup menjadi efek yang dirasakan paling awal pada disrupsi, penggunaan teknologi menjadi syarat bagi sebuah bisnis untuk berkembang dan bertahan diantara ekosistem bisnis itu sendiri, dalam hal ini UKM menjadi sektor usaha yang rentan menghadapi era disrupsi, pembekalan dan penerapan teknologi bagi UKM menjadi syarat agar UKM dapat terus berkembang. Dalam hal pengembangan teknologi informasi ini maka perancangan mengambil objek pada Kampung Kue di Rungkut Penjaringan Kota Surabaya, Selama ini UKM di Kota Surabaya tersebut hanya dikenal melalui brosur maupun secara lisan kepada masyarakat. Hal ini dirasa kurang efektif karena membutuhkan waktu yang lama dan informasi yang didapat pun kurang lengkap. Oleh karena itu perancangan aplikasi online market place UKM Kampung Kue Rungkut Penjaringan sebagai media informasi, transaksi dan sebagai media yang mampu meningkatkan kredibilitas para pelaku usaha produksi makanan tradisional. Peranan aplikasi ini diharapkan menjadi bagian yang terintegrasi dengan branding Kampung Kue Rungkut Penjaringan, dimana salah satu branding yang dirancang adalah branding melalui media online, aplikasi Kampung kue diharapkan dapat menjadi pilihan konsumen jaman kini untuk mencari kebutuhannya.
\end{abstract}

Kata kunci: Aplikasi, marketplace, kampung kue, UKM.

\begin{abstract}
Today the rapid development of technology has consequences for disruption. Changes in way of life and lifestyle are the earliest felt effects on disruption. The use of technology is a condition for a business to develop and survive among the business ecosystem itself. In this case, Small Medium Enterprise (SME) is becoming a business sector that is vulnerable to the era of disruption. Provisioning and application of technology for SMEs is a condition for SMEs to continue growth. In terms of the development of this information technology, the design takes the object in Kampung Kue in Rungkut Penjaringan, Surabaya. So far, the SME in Surabaya is only known through brochures or verbally to the public. This is considered ineffective because it requires a long time and the information obtained is also incomplete. Therefore, designing an online marketplace application for SME Kampung Kue Rungkut Penjaringan as a medium of information and transactions can increase the credibility of traditional food production businesses. The role of this application is expected to be an integrated part of the Kampung Kue Rungkut Penjaringan branding, where one of the branding designed is branding through online media. The Kampung Kue application is expected to be the choice of consumers today to look for their needs.
\end{abstract}

Keywords: Application, marketplace, kampung kue, SME.

\section{Pendahuluan}

Kampung Kue Rusun Penjaringan, Kelurahan Penjaringan Sari merupakan salah satu sentra produksi kue tradisional dan jajanan yang cukup dikenal di Surabaya. Salah satu produksinya yaitu keripik melinjo yang telah dipasarkan hingga ke Thailand. Selain keripik kampung kue juga menjual aneka kue basah dan kue kering. Meskipun cukup terkenal luas tetapi harga jual produk terbilang sangat murah. Keuntungan yang didapat harus digunakan untuk promosi dan membuat kemasan.

Para produsen kue selama ini hanya menggunakan kemasan yang seadanya, selain kurang aman juga tidak ada identitas yang membedakan produk kamoung kue dengan lainnya. Dengan latar belakang tersebut dapat diambil kesimpulan, pengembangan Kampung Unggulan Kue dilakukan 
melalui perancangan program branding dan promosi yang terintegrasi, dimana salah satu pendukung branding terintegrasi adalah terorganisirnya komunitas penjual dan pembeli dalam satu kegiatan pemasaran.

Online marketplace merupakan salah satu faktor penentu keberhasilan pemasaran sebuah produk di era disrupsi sekarang. Online Marketplace menjadi sarana pendukung aktivitas pemasaran yang bersifat mudah diakses, fleksibel dan berimplikasi luas, online marketplace dalam era kekinian menjadi etalase produk yang ditawarkan dan menjadi sebuah keharusan bagi Kampung Kue dalam rangka tetap menekan biaya promosi namun dapat menambah standar kemasan serta membangun kesadaran merk Kampung Kue baik untuk pelanggan lama maupun pada calon konsumen baru.

Pengembangan Kampung Unggulan Kue ini perlu didukung oleh sebuah program branding yang terintegrasi melalui sebuah identitas visual, langkah yang kemudian dilakukan dalam rangka program branding adalah penciptaan sebuah kegiatan promosi. Maka perancangan online marketplace kampung kue diarahkan untuk mendukung kegiatan promosi.

Website merupakan salah satu media informasi dan komunikasi yang banyak diakses oleh masyarakat, penggunaan media website sebagai sarana informasi terhitung lebih murah dibanding menggunakan media cetak. Namun tren penggunaan website telah bergeser menjadi aplikasi mobile yang lebih praktis dan prestisius bagi beberapa kalangan pengguna.

Dengan melakukan penggalian data mengenai aktivitas dan minat segmen pengguna aplikasi serta kajian literatur mengenai metode mengembangkan website menjadi sebuah aplikasi mobile yang maka dirancanglah aplikasi online market place kampung kue rungkut penjaringan.

\section{Tinjauan Pustaka}

\section{Desain Website}

Desain website adalah sebuah perencanaan, pembuatan dan pembaharuan situs web. Desain website sama dengan desain fashion, selalu berubah mengikuti perkembangan zaman. Ada tren yang sama sekali baru dan ada pula yang merupakan pengulangan dari tren beberapa tahun ke belakang. Namun, elemen-elemen esensial di dalamnya tidak banyak yang berubah (Griffiths, 2015). Adanya elemen desain website tidak hanya agar menampilkan website yang estetis tetapi juga meningkatkan user experience (UX) (Kujala, 2011).
Desain web melibatkan prinsip arsitektur informasi, struktur website, user interface, navigasi,dan grafis (Kujala, 2011). Desain adalah proses mengumpulkan gagasan, mengatur dan menerapkan secara estetika yang diikat oleh prinsip-prinsip tertentu untuk tujuan tertentu. Berdasarkan Griffiths (2015) dan Shneiderman (1998), desain web tidak terlepas dari disiplin ilmu dan keterampilan yang mengikutinya, desain web memiliki beberapa elemen visual seperti:

\section{a. Layout}

Semua komponen sejajar dengan grid baseline yaitu 8 dp persegi untuk handphone, tablet dan desktop. Sedangkan untuk ikongrafi, tipografi dan elemen-elemen lain sejajar dengan 4dp. Untuk grid layout terdiri dari tiga elemen: coloumn, gutters, dan margin. Lebar kolom ditentukan oleh breakpoint di mana layar dilihat apakah itu breakpoint di handphone, tablet, atau ukuran lainnya.

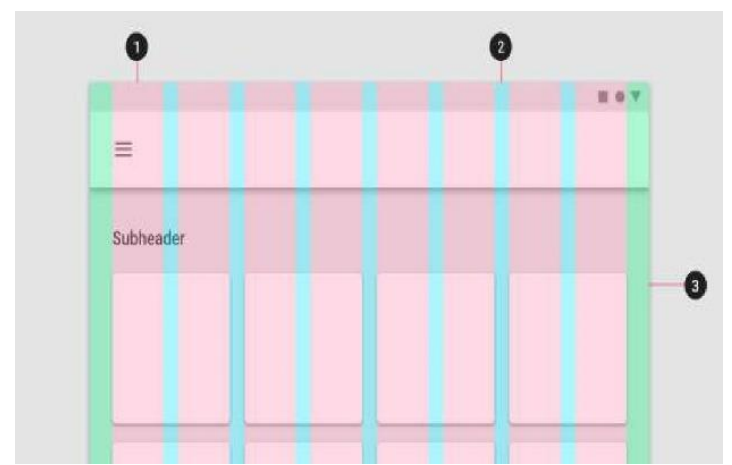

\section{Gambar 1. Grid Line}

Gutters adalah ruang diantara kolom yang membantu memisahkan isi konten. Lebar gutters yang direkomendasikan pada responsive web dalam mobile dengan breakpoint 360dp yaitu menggunakan 16dp gutter. Sedangkan untuk tablet pada breakpoint 600dp, tata letak grid menggunakan 24dp gutters.

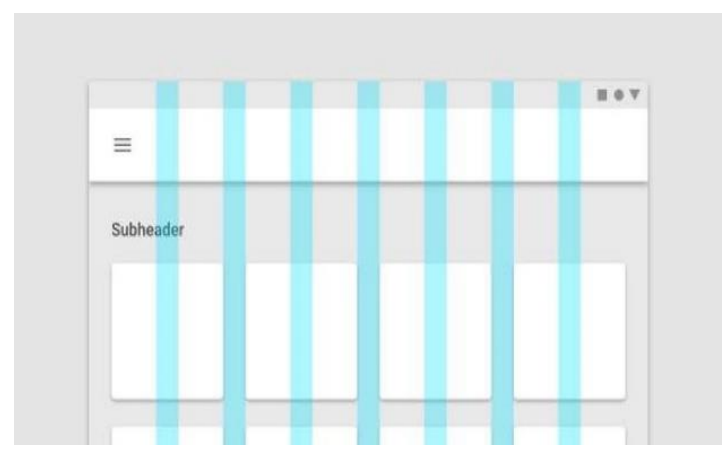

Gambar 2. Rekomendasi gutters pada tablet

Untuk memastikan kepadatan informasi yang seimbang dan berfungsi dengan baik, ukuran objek minimal harus dengan ukuran $48 \mathrm{dp}$ x $48 \mathrm{dp}$. 


\section{b. Color}

Warna sangat berpengaruh dalam sebuah desain. Skema warna dalam desain harus bisa mewakili karakter yang diinginkan, dalam sebuah UI design, terdapat beberapa warna yang digunakan. Palet warna ini awalnya dibuat oleh desain material di tahun 2015 secara harmonis dan dapat dipilih sesuai kebutuhan.

Dengan warna primer dan sekunder dengan opsi warna terang dan lebih gelap sebagai pemisah satu dan lainnya. Dengan memberi warna yang memenuhi standar aksesibilitas. Color palette yang digunakan dalam website diambil dari tone warna yang playful sehingga memberikan kesan ceria, muda dan bersemangat sesuai segmen aplikasi marketplace.

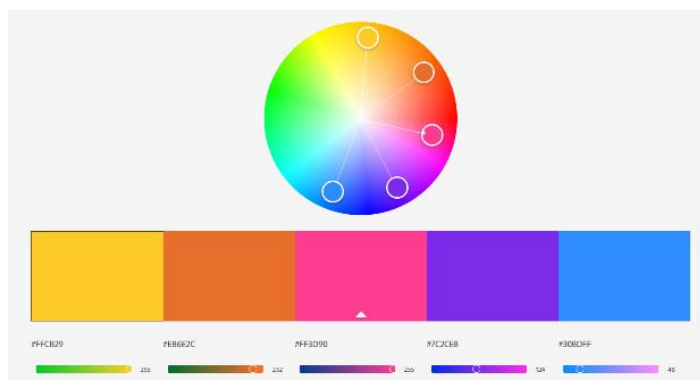

Gambar 3. Rekomendasi warna

\section{c. Icon}

Pada website terdapat guideline dalam pembentukan besaran sebuah ikon. Guideline tentang besaran suatu ikon agar kompatibel dan berjalan dengan baik menurut rekomendasi dari Google material design adalah seperti contoh berikut:

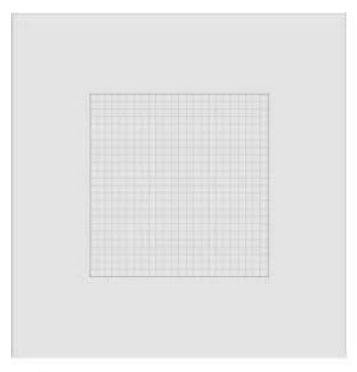

Grid

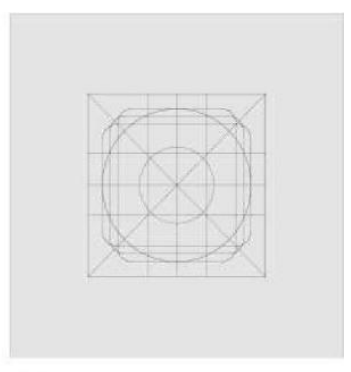

Gambar 4. Grid dan Keyline

\section{Aplikasi Mobile (App) berbasis Web}

Mobile app berbasis web adalah aplikasi web yang diformat untuk smartphone dan tablet yang dapat diakses melalui web browser dari perangkat mobile atau menggunakan launcher website. Seperti aplikasi web konvensional, app mobile web dibangun dengan 4 teknologi inti: HTML (mendefinisikan teks statis dan gambar), CSS (mendefinisikan gaya dan presentasi), JavaScript (mendefinisikan interaksi dan animasi) dan Android Studio atau perangkat lunak yang mampu membuat aplikasi yang berjalan dengan baik pada sistem operasi android.

Karena apps web berbasis browser, app tersebut dimaksudkan dapat dijalankan pada berbagai seri OS android, Mobile app berbasis web normalnya mengunduh data dari server pusat web atau hosting setiap kali dijalankan, sehingga aplikasi marketplace Kampung Kue berbasis sistem online apabila digunakan oleh pengguna.

\section{Bagan Informasi}

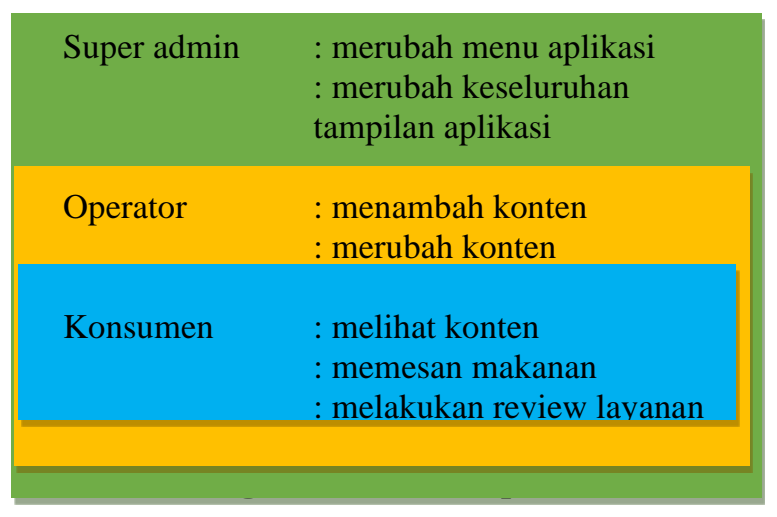

Skema informasi aplikasi berbasis website yang disajikan dibagi menjadi 2 pengguna, yaitu operator dan konsumen, operator memiliki akses untuk merubah informasi dari konten yang disajikan dan memiliki akses untuk membagi pekerjaan pesanan makanan kepada produsen dan meneruskan pesanan kepada kurir untuk mengantar pesanan kepada konsumen, pembayaran dilakukan melalui rekening atas nama Kampung Kue Rungkut Penjaringan dan akuntabilitasnya diketahui oleh semua produsen. Kerja operator secara manual masih digunakan untuk menjembatani kesenjangan pengetahuan dan budaya penggunaan teknologi oleh produsen makanan di Kampung Kue.

Bagan bagian konsumen dapat melihat informasi setiap produk yang ditampilkan dalam aplikasi, konsumen dapat memesan dan merubah pesanan, konsumen dapat masuk aplikasi tanpa melakukan pendaftaran, namun untuk memesan makanan konsumen harus melakukan pendaftaran terlebih dahulu.

\section{Hasil dan Pembahasan}

\section{Desain Website Marketplace}

Domain digunakan sebagai alamat akses situs marketplace. Domain yang digunakan adalah IP 
address, di mana hal ini salah satunya adalah untuk membatasi akses domain oleh pihak pengguna di luar aplikasi karena marketplace ini ditujukan hanya dapat diakses melalui aplikasi mobile saja.

Langkah pertama adalah mengakses control panel (CPanel) pada IP address yang telah didaftarkan dan melakukan instalasi Wordpress sebagai engine yang digunakan untuk backend dan frontend karena engine tersebut cukup fleksibel dan memiliki ekosistem pendukung yang cukup luas.

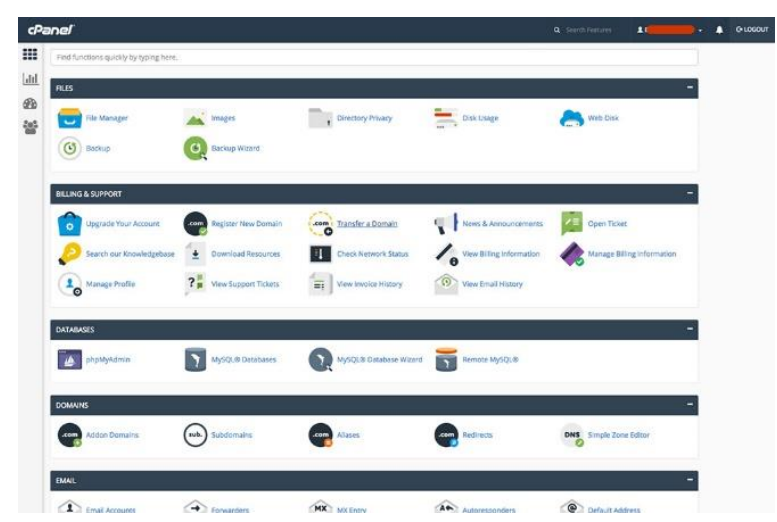

Gambar 6. Halaman control panel website

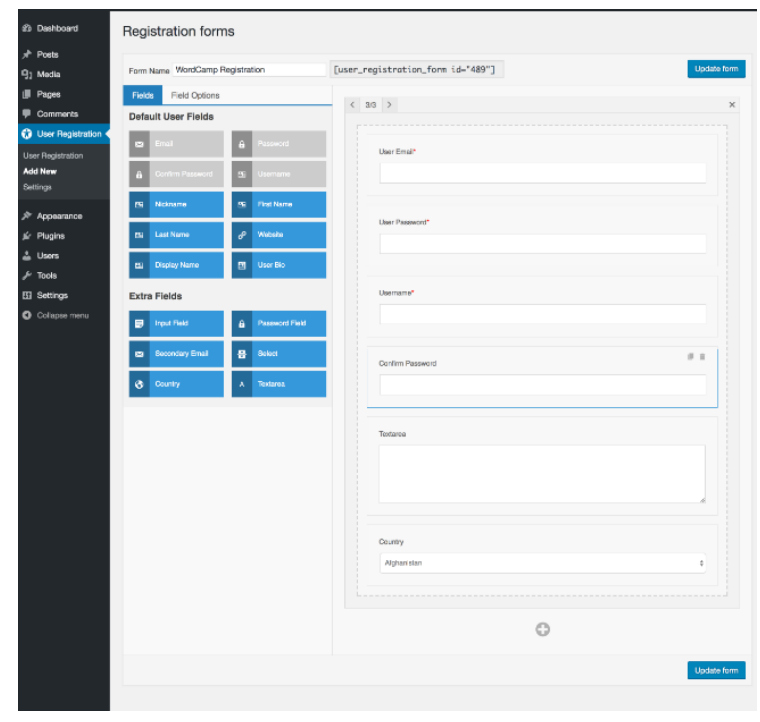

Gambar 7. Halaman form registrasi

Halaman registrasi dibuat lengkap dengan memasukkan identitas diri, alamat, email dan nomor handphone yang aktif digunakan oleh konsumen aplikasi. Hal ini untuk menjamin transaksi yang dilakukan adalah nyata, dan memudahkan operator dalam menginformasikan promo atau kegiatan di aplikasi Kampung Kue.

Brand strategy untuk Rusun Kue adalah pluralistik di mana Rusun Kue merupakan brand induk yang membawahi brand-brand pribadi dari setiap produsen makanan di Kampung Kue.

\section{Desain aplikasi peluncur versi mobile}

Aplikasi marketplace online Kampung Kue dibatasi penggunaannya melalui aplikasi mobile atau android yang banyak digunakan oleh segmen yang dituju. Metode aplikasi peluncur website yang dipilih untuk mengakses marketplace online dan dalam membangun aplikasi peluncur digunakan perangkat lunak yang bersifat online. Hal tersebut dilakukan dengan mempertimbangkan kemudahan dan efektivitas ukuran aplikasi yang apabila dikerjakan secara online akan menghasilkan ukuran file yang cukup ringan. Penggunaan aplikasi online dipilih untuk membangun aplikasi launcher market place.

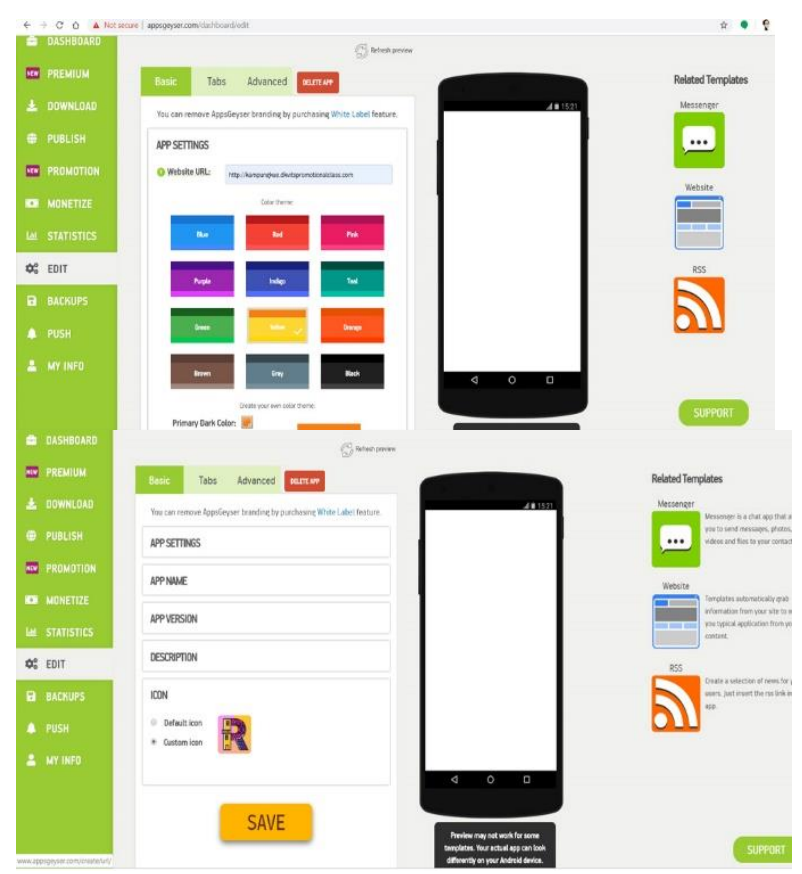

Gambar 8. Penggunaan perangkat lunak online untuk membuat aplikasi launcher

Implementasi warna identitas Kampung Kue dari konsep integrasi branding yang telah dilakukan didapatkan hasil rancangan baik untuk konten website maupun konten Play Store, di mana distribusi aplikasi adalah melalui Play Store Google. Hal tersebut untuk memudahkan konsumen dalam mendapatkan aplikasi, sekaligus untuk menambah kesan modern dari Kampung Kue itu sendiri.

Pada Play Store terdapat bagian informasi yang wajib untuk diisi oleh pengembang aplikasi, berikut adalah desaain atau konten pada bagian informasi di Play Sstore tersebut. 


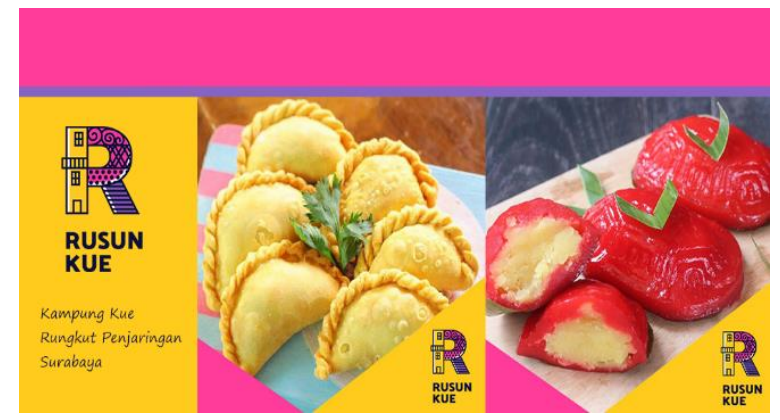

Gambar 9. Tampilan pada banner Google Play Store

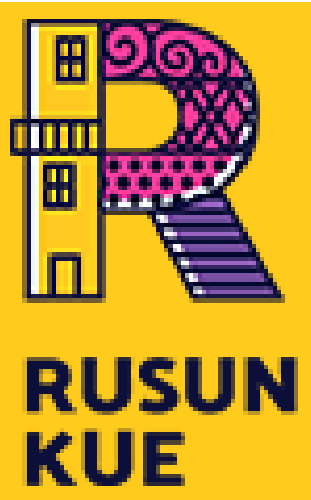

Gambar 10. Tampilan pada pada promo graphic Google Play Store
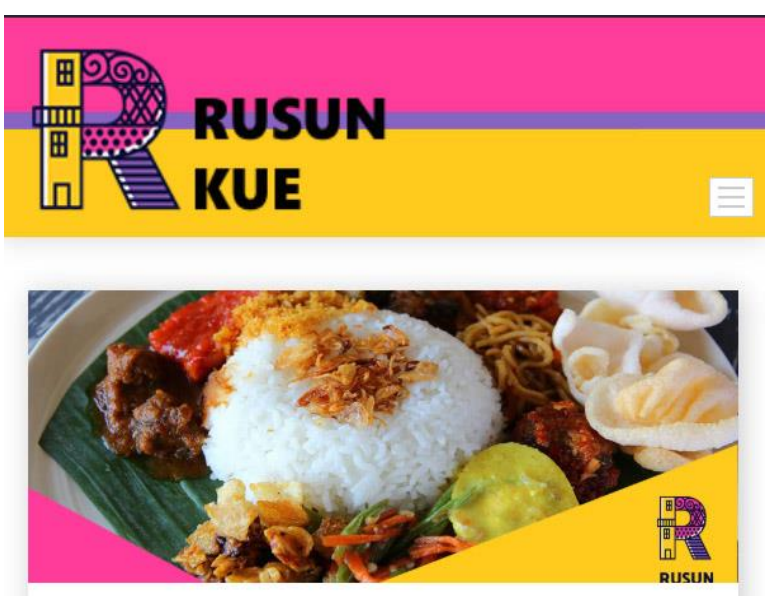

$$
\begin{aligned}
& \text { NASI CAMPUR } \\
& \text { (1) By operator } \\
& 0 \text { Nov 22, } 2019
\end{aligned}
$$

harga: Rp 25.000,- / porsi varian campuran : nasi - tumis - mie - aya $\mathrm{m} 1$ potong - tempe

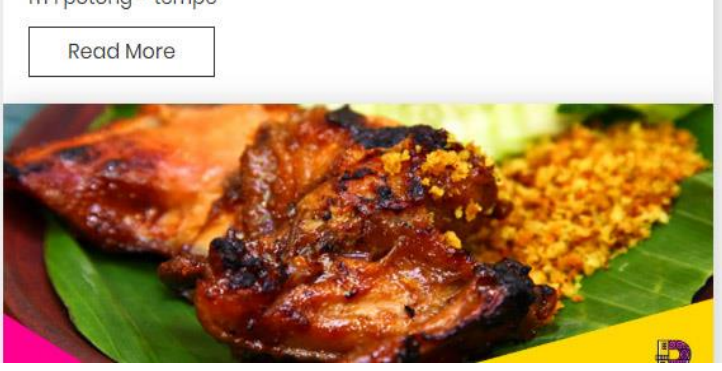

Gambar 11. Tampilan halaman utama aplikasi online market place Kampung Kue

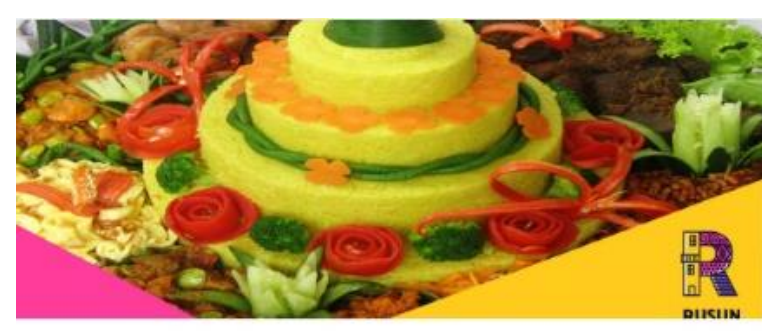

NASI TUMPENG

(C) By operator

- $0 \simeq$ Nov 22, 2019

Harga : 5 porsi : Rp 120.000,- 7 porsi : Rp 160.000,- 9 porsi : Rp 200.000,- 12 porsi:

Read More

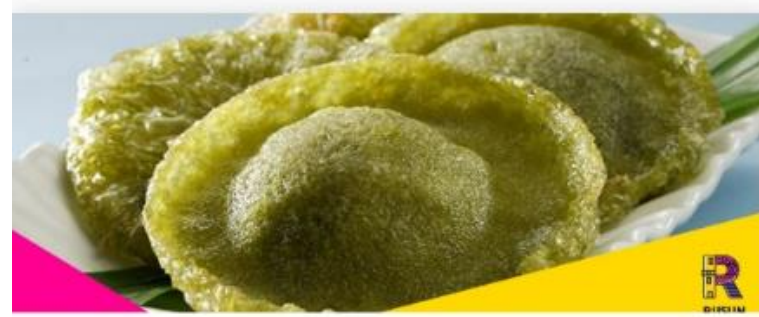

KUE CUCUR

(1) By operator

- 0 - Nov 22, 2019

Harga : Rp 20.000,- / box (isi 6) Varian rasa : pandan vanila green tea

Gambar 12. Tampilan lanjutan halaman utama pada aplikasi Rusun Kue

\section{NASI TUMPENG}

(1)

operator

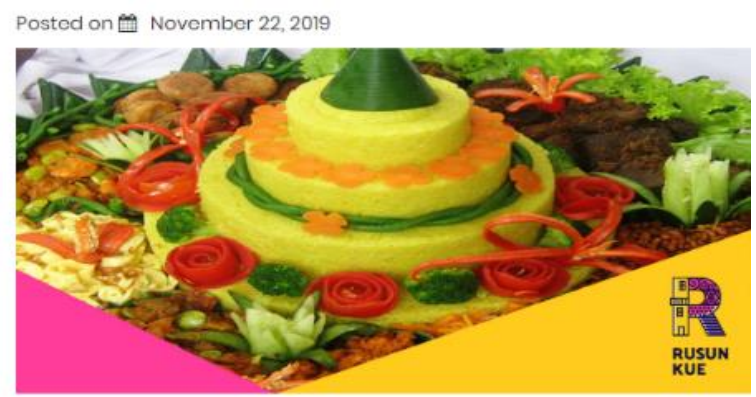

Harga:

- 5 porsi : Rp 120.000,-

- 7 porsi: Rp 160.000-

- 9 porsi : Rp 200.000-

- 12 porsi : Rp 260.000 -

\section{Tambahkan pesanan}

- modifikasi lauk

- modifikasi sayur

- modifikasi pelengkap

- modifikasi tampilan

Modifikasi komposisi

Gambar 13. Tampilan halaman menu makanan pada aplikasi Rusun Kue 


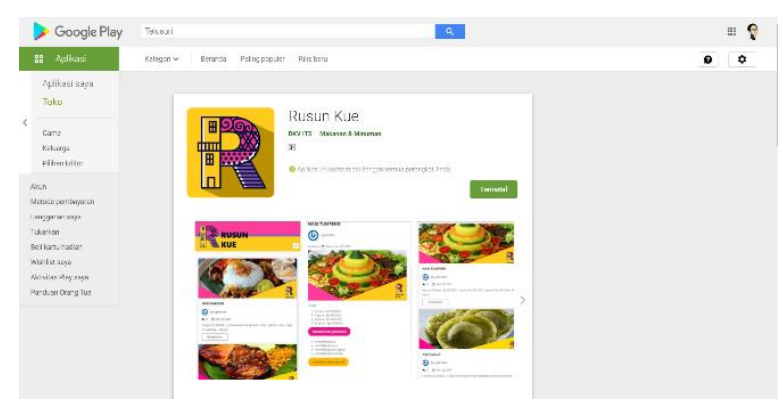

Gambar 14. Tampilan aplikasi pada Google Play Store versi desktop

$\leftarrow$

Q :

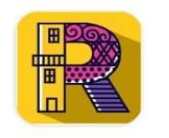

\section{Rusun Kue}

DKVITS
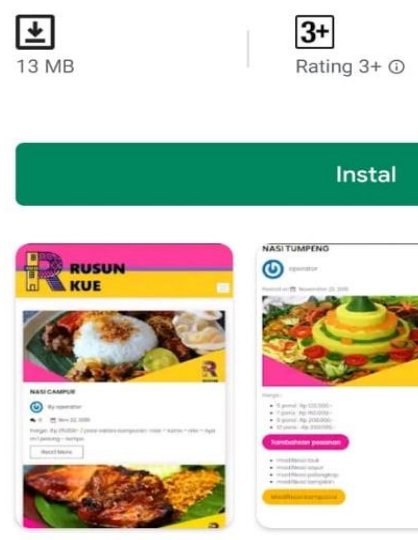

Instal

Tentang aplikasi ini
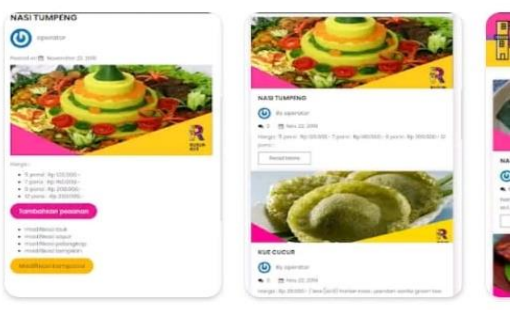

Aplikasi Online Market Place Kampung Kue Rungkut Penjaringan

Makanan \& Minuman

\section{Ulasan Anda}

Gambar 15. Tampilan aplikasi pada Google Play Store versi mobile android

\section{Simpulan}

Dalam pembuatan aplikasi marketplace online ini dibutuhkan berbagai macam proses yang kompleks dan beberapa macam keahlian, tidak hanya keahlian teknis dan desain visual namun juga keahlian berkomunikasi yang baik dan studi pengalaman pengguna untuk mendapatkan hasil yang terbaik.

Aplikasi dapat berjalan dengan baik pada banyak perangkat android, aplikasi dapat berjalan dengan baik pada android versi 5.0 atau versi diatasnya, tidak diperlukan spesifikasi perangkat yang tinggi, hanya membutuhkan koneksi data untuk membuka situs data online, tampilan aplikasi pada perangkat android berjalan baik, aplikasi tidak dapat digunakan dalam mode tampilan landscape pada semua perangkat android.

Pengoperasian pencatatan dan pembagian transaksi pembelian dilakukan secara manual melalui operator aplikasi yang bekerja secara online. Penggunaan 1 rekening bersama di internal produsen dapat berjalan baik, dokumentasi pembagian pesanan dan transaksi dapat diakses oleh setiap produsen makanan yang berjumlah 25 produsen.

Skema informasi pada aplikasi yang mudah digunakan oleh pelanggan dan konsumen baru menjadi kelebihan aplikasi sekaligus menjadi kelemahan dalam hal pengalaman pengguna yang akan cepat merasa bosan, diperlukan penelitian dan pengujian lanjut untuk membangun pengalaman pengguna yang lebih menarik dan imersif bagi pengguna aplikasi.

Penggunaan tenaga operator pada saatnya akan menemukan titik jenuh dan ketidak efektifan yang dikarenakan bertambahnya transaksi, dalam hal ini perlu dilakukan penelitian lanjutan untuk membangun sebuah system yang berbasis Artificial Intelligent dan big data yang bekerja menggantikan kerja operator manusia, operator manusia akan lebih efektif apabila melakukan fungsi kontrol kualitas dan evaluasi transaksi, sekaligus menjalankan fungus Customer Relationship Marketing yang lebih mengedepankan pendekatan secara emosial kepada setiap pelanggan, baik melalui sekam promo yang ditawarkan, balasan chat yang tepat waktu dan mengenai pokok komunikasi, penggunaan gaya Bahasa yang sesuai dengan segmentasi pelanggan dan bentuk-bentuk strategi marketing yang tidak dapat dilakukan oleh mesin.

\section{Daftar Pustaka}

Griffiths, Stephen. "Mobile App UX Principles". Google, 2015.

Kujala, Sari; Roto, Virpi; Väänänen-Vainio-Mattila, Kaisa; Karapanos, Evangelos; Sinneläa, Arto. "UX Curve: A method for evaluating long-term user experience". Interacting With Computers, 2011: 473-483.

Ben Shneiderman. Designing User Interface: Strategies for Effective Human Computer Interaction. Michigan University: Addison Wesley Longman, 1998: 74.

Hanington, Bruce \& Martin, Bella. Universal Methods of Design: 100 Ways to Research Complex Problems. Pennsylvania: Rockport Publisher, 2012.

Rainer, R. Kelly Jr and Casey G. Cegielski. Introduction to Information System: Support and Transforming Business Fourth Edition. New Jersey: John Wiley and Sons, Inc., 2012.

Ridder, D. Lennard. 2018. 9 Cutting Web Design Trens for 2018. 